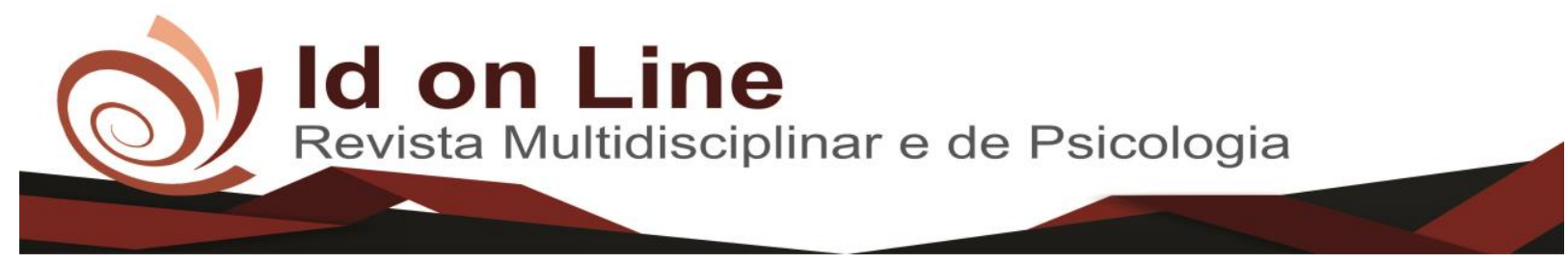

Artigo

\title{
Diversidade Sexual no Ambiente Escolar: O Exemplo do Campus Iguatu do IFCE
}

Eliza Marta Gonçalves Ferreira ${ }^{1}$; Antonia Edilzerina Rodrigues de Mendonça²;Maria de Fátima de Morais Alves ${ }^{3}$

Resumo: O presente artigo apresenta uma reflexão sobre como o conceito de inclusão é tratado nas normativas e discursos institucionais. Traz como cenário o campus Iguatu do Instituto Federal de Educação, Ciência e Tecnologia do Ceará (IFCE) para ilustrar por meio de exemplos concretos como se efetiva ou não a inclusão quando alargada para um público distinto da pessoa com deficiência. Aborda, embora de forma breve e incipiente, como o significado de inconsciente se manifesta nas linguagens dos regulamentos, nas falas e práticas dos que detém poder decisório entre os atores que compõem a instituição. Remete o conceito de inclusão para a diversidade sexual, no intuito de perceber a escola como reprodutora ou não de preconceitos, discriminação e violação de direitos no processo educativo.

Palavras-Chave: Inclusão; Escola; Diversidade sexual.

\section{Sexual Diversity in the School Envairoment: The IFCE Campus Iguatu example}

\begin{abstract}
The present article shows a reflection on how the inclusion concept is treated in instituitional norms and discourses. It brings the Iguatu campus of Instituto Federal of Educação, Ciência and Tecnologia of Ceará (IFCE) as a scenario to ilustrate by concrete examples how or how not to include inclusion when broadened to a public distinct from disabled person. It adresses, albeit briefly and unconsciously how the meaning of the uncouscious manifests itself in the languages of the regulations, in the speeches and practices of those persons hold the decisionmaking power among the actors that make up the instituiton. It refers to the concept of inclusion for sexual diversity, in order to perceive the teachering unit as reproductive or not of prejudices, discrimination and violation of rights in the educational process.
\end{abstract}

Keywords: Inclusion, school, sexual diversity

\section{Introdução}

\footnotetext{
1 Mestranda do Mestrado em Educação Agrícola do PPGEA/UFRRJ. Assistente Social do IFCE campus Iguatu. elizamarta.ifce@gmail.com

${ }^{2}$ Mestranda do Mestrado em Educação Agrícola do PPGEA/UFRRJ. Técnica em Assuntos Educacionais. Pró-reitoria de Gestão de Pessoas - IFCE. edilzerina@gmail.com

${ }^{3}$ Mestranda do Mestrado em Educação Agrícola do PPGEA/UFRRJ. Auxiliar em Administração do IFCE - campus Iguatu. fatimamoraisalves@hotmail.com
} 
As produções a respeito da inclusão, notadamente na Política de Educação, sobejamente referem-se à inclusão da pessoa com deficiência, especialmente a partir da obrigatoriedade da oferta de vagas para pessoas com deficiência nas salas de ensino regular. Entretanto, tal como defendida pelos organismos de defesa dos direitos humanos que inspiram os acordos, as declarações e as legislações, a concepção de Inclusão não se restringe a aceitação da matrícula da pessoa com deficiência, mas, deve estar acompanhada das condições adequadas de atendimento desse sujeito. De acordo com Gouvêa,

O verdadeiro pressuposto de Inclusão, não cabe na "objetalização" da criança, deixando de enxergá-la como um sujeito, para enxergar uma patologia. Isto, por si só, já inviabiliza o ato educativo, pois parte de significações estereotipadas acerca do aluno. (GOUVÊA, 2008, p. 51).

Tampouco, a Inclusão está limitada a esse público (da pessoa com deficiência) e ao aspecto cognitivo - fator preponderante quando dos relatos das dificuldades de profissionais da educação em lidar com estudante com deficiência. Portanto,

\footnotetext{
Pensar a escola inclusiva no sentido mais amplo, ou seja, que atenda a todos (as) sem discriminação, preconceito ou qualquer tipo de violação de direitos, é assumir que a instituição escolar é espaço heterogêneo de contradição, de conflitos, mas é antes de tudo um ambiente educativo, e como tal deve trabalhar o seu projeto na perspectiva da diversidade, compreendendo-a como possibilidade de aprendizagens nos campos afetivo, cognitivo, político-social e ético. (SILVA, 2012, p.33).
}

Sustentadas por esta compreensão de inclusão e de escola podemos concluir que outras expressões singulares do jeito de ser da pessoa humana necessitam ser reconhecidas e respeitadas no ambiente escolar, dentre as quais, tem destaque neste texto a diversidade sexual. Para guiar nossa reflexão a respeito de como se processa a inclusão ou não de outros sujeitos diferentes (que não pessoas com deficiência), tomamos como exemplo empírico a Unidade Cajazeiras do campus Iguatu do Instituo Federal de Educação, Ciência e Tecnologia do Ceará - IFCE para ilustrar o abismo que separa os discursos e as práticas no interior da unidade escolar no que tange a inclusão. A escolha deste campus se deve ao fato deste oferecer na sua estrutura organizacional a matrícula em regime de internato.

\section{O Internato do IFCE Campus Iguatu}


Desde a sua criação em meados dos anos 1980 a Escola Agrotécnica Federal de Iguatu (à época da expansão do ensino agrícola no interior do Brasil para atender filhos de agricultores) admite meninos em regime de internato. As instalações preparadas para acolher 200 (duzentos) estudantes foram por mais de 20 anos (desde os primórdios até o início dos anos 2000) bastante disputadas por adolescentes de todas as regiões do Estado do Ceará e estados vizinhos. Atualmente, não chega a 100 (cem) o número de estudantes em regime de internato.

A presença da homossexualidade e da homoafetividade no interior do internato desde os primórdios é conhecida por todos os que fazem a instituição. Porém, de acordo com relatos de servidores mais antigos tudo acontecia com mais discrição. A partir do funcionamento de curso superior no turno noturno, em meio a um contexto de maior liberdade de manifestação da identidade de gênero ${ }^{2}$ está hoje, não apenas mais evidente essa presença, mas também, consideravelmente aumentada. Percebemos no cotidiano do internato do campus nos dias atuais que "os estudantes homossexuais normalmente se agrupam em um alojamento; se tratam por "mulher"; são muito ativos nas atividades escolares e da coordenação; outra característica forte é que eles mobilizam nas suas cidades de origem amigos que se identificam como homossexuais ou que têm uma "tendência" para virem se matricular na instituição" (fala de Antônio Gilvan Teixeira, Coordenador Geral da CGAE)².

Benelli (2012) chama a atenção para o fato de estarmos no século XXI utilizando tecnologias sociais que remontam séculos, como é o caso do Internato - instituições totais disciplinares, "um viveiro ou uma estufa que funciona como instrumento para modelar, mudar e transformar pessoas." (BENELLI, 2012, p.107). Entretanto, em um contexto de transformações societárias, "novas formas de relacionamento, de produção, de consumo e de produção de subjetividade se manifestam" (BENELLI, 2012, p.105).

Comportamentos preconceituosos e discriminatórios em relação à orientação sexual de estudantes internos visualizados nas gozações, nas brincadeiras maldosas e até em agressões físicas, expressam processos de exclusão no interior da instituição que necessitam de um tratamento pelo viés de ações educativas que oportunizem o acolhimento às diferenças, a qual

\footnotetext{
${ }^{2}$ Identidade de gênero - Diz respeito à percepção subjetiva de ser masculino ou feminino, conforme os atributos, os comportamentos e os papeis convencionalmente estabelecidos para homens e mulheres. Conforme encontrado em: BARRETO; ARAÚJO; PEREIRA, 2009, p. 43.

${ }^{2}$ Coordenação Geral de Apoio ao Educando (CGAE), setor composto por equipe multidisciplinar estreitamente ligada aos internos.
} 
exige mudança na forma como se estruturam, como são pensadas e como se lida com elas (GÔUVEIA, 2008). Tendo em vista que,
A dinâmica psicossocial totalitária e disciplinar que se estabelece automaticamente sobre o conjunto dos atores institucionais promove a vigilância e o controle mútuo, gerando relações de poder antagônicas entre diversos subgrupos de alunos internados e entre os dirigentes e o conjunto dos internados. (BENELLI, 2012, p.109).

Diante, porém, de cenário marcado por atitudes preconceituosas e discriminatórias no ambiente escolar, temos a escola como reprodutora da naturalização e banalização destas. Alguns exemplos, elencados a seguir, nos dão mostra de como a questão da sexualidade e das relações de gênero são mal compreendidas no ambiente institucional, e, portanto, necessitam ser objeto de estudo e de discussão tanto de educandos quanto de educadores:

- Pesquisa realizada por Sheila Teodósio, egressa do curso de Serviço Social do campus, para o seu Trabalho de Conclusão de Curso (TCC) intitulado "A inserção de mulheres nos cursos Técnico em Agropecuária e Agroindústria" - cursos majoritariamente masculinos - revelou indícios de violência (simbólica, psicológica) contra a mulher no ambiente de sala de aula e mais fortemente nas aulas práticas;

- Durante a realização do curso Educação, Sexualidade e Relações de Gênero - execução do projeto de intervenção desenvolvido pelo estagiário de Serviço Social Jonas Mateus Piancó, em cumprimento à atividade da disciplina de Estágio Supervisionado II, que teve como público alvo estudantes dos cursos técnicos integrados de agropecuária e agroindústria - as falas de meninos que participaram do curso denotam a forma preconceituosa como são tratados aqueles que manifestam a sua orientação sexual fora dos padrões estabelecidos pela sociedade. $\mathrm{O}$ curso foi debochadamente nominado como "o curso dos veados";

- Em uma das três etapas do Projeto de intervenção Escola sem homofobia - também desenvolvido por estagiárias do curso de Serviço Social - alguns meninos expuseram situações de violência vivenciadas no interior da unidade escolar em razão da sua orientação sexual;

- Mais recentemente, em 8 de março de 2017 - Dia Internacional da Mulher - o projeto Mulher: o mundo em movimento, idealizado e executado pelos mestrandos do curso de 
Mestrado em Educação Agrícola em cumprimento à atividade da disciplina Internalizando a Inter/Transdisciplinaridade, foi mais uma demonstração do quanto é necessário ainda caminhar para romper com as desigualdades de gênero. Diante da pouca adesão dos docentes no trabalho prévio em sala de aula e do conjunto dos servidores na participação no evento de culminância, é possível constatar a ausência de discussão em torno da temática de gênero.

Esses exemplos são registros de como a discriminação, o preconceito, a violência contra a mulher e sobre a orientação sexual que foge aos padrões heteronormativos são naturalizados. Tais exemplos, aliados ao relato e ao testemunho de fatos cotidianamente ocorridos, evidenciam pelo menos duas falhas no processo educativo da instituição: a falta de preparação (principalmente de docentes) em trabalhar a sexualidade e as relações de gênero como tema transversal; bem como a omissão (principalmente da gestão) diante de situações que precisam ser vistas, analisadas e trabalhadas por diferentes olhares, ou seja, precisam considerar os profissionais das diversas áreas do conhecimento para o planejamento coletivo de ações que possibilitem a efetivação da educação inclusiva. Adotar, enfim, o ambiente escolar como um lugar privilegiado de construção das identidades individuais e coletivas dos sujeitos, como um lugar propício ao exercício dos direitos e do respeito à diferença. Do contrário, havendo falhas nos objetivos e finalidades educacionais a que se propõe, a escola se caracterizará apenas como disciplinadora e normalizadora (BENETTI, 2012) de comportamentos e condutas.

\section{Inconsciente e Educação}

Conceitos da psicanálise construídos a partir dos estudos de Freud sobre a consciência humana são fundamentais ao entendimento acerca do funcionamento das instituições educativas, especialmente aquelas que lidam com modalidade de matrícula que acolhe seus alunos como "moradores", ou seja, além de oferecer as condições da educação escolarizada - à qual é exigida a formação integral, portanto, além da aprendizagem cognitiva - oferta também as condições de habitabilidade - ainda que por curto período. No caso do IFCE campus Iguatu, 
a instituição de ensino é corresponsável (junto com a família) pelo cuidado e educação de estudantes internos. De acordo com Gouvêa,

Quando a educação é atravessada pelo pensamento psicanalítico, a terminologia deficiência/diferença ganha novos contornos. O sujeito da diferença passa a sujeito da singularidade, situado em um contexto educativo cuja tarefa nunca termina. (GOUVÊA, 2008, p.38).

Necessário se faz, pois, acorrermos à literatura que nos informe sobre conceitos de Consciente e Inconsciente, no sentido de possibilitar a aproximação destes conceitos com os conteúdos de instrumentos normativos e atitudes dos vários sujeitos que povoam a escola, por entendermos que a elaboração destes é perpassada por aqueles, considerando que são elaborados por pessoas humanas.

Uma leitura breve da teoria de Freud nos permite delinear três níveis da consciência: o Consciente, o Pré-consciente e o Inconsciente.

\footnotetext{
Consciente - diz respeito à capacidade de ter percepção dos sentimentos, pensamentos, lembranças e fantasias do momento;

Pré-consciente - relaciona-se com os conteúdos que podem facilmente chegar à consciência;

Inconsciente - refere-se ao material não disponível à consciência ou ao escrutínio do indivíduo.

No entanto, o ponto nuclear da abordagem psicanalítica de Freud é a convicção da existência do inconsciente como:

a) Um receptáculo de lembranças traumáticas reprimidas;

b) Um reservatório de impulsos que constituem fonte de ansiedade, por serem socialmente ou eticamente inaceitáveis para o indivíduo. (Freud e o Inconsciente, 2008).
}

Diante destes conceitos e a partir da constatação de que os motivos das lembranças traumáticas reprimidas e dos impulsos geradores da ansiedade estão intimamente associados à sexualidade humana podemos compreender por que as temáticas da sexualidade e das relações de gênero, embora incluídas como temas transversais nos currículos do ensino médio, estão ausentes dos conteúdos abordados em sala de aula ou não são devidamente trabalhadas pelos docentes. Concordamos com o pensamento de Gouvêa quando diz que,

\footnotetext{
A educação é o principal alicerce da vida social. Ela transmite e amplia a cultura, estende a cidadania, constrói saberes para o trabalho. Mais do que isso, ela é capaz de ampliar as margens da liberdade humana, à medida que a relação pedagógica adote, como compromisso e horizonte ético-político, a solidariedade e a emancipação. (GOUVÊA, 2008, p.54).
} 
Com este entendimento sobre a educação e sobre a escola como lugar da educação escolarizada, que congrega distintas expressões da sexualidade humana, apoiadas pelas contribuições da psicanálise, deve evitar que recalques de pais e educadores assumam o formato de repressão, discriminação, enfim, de violência contra as diferenças, tendo em vista que,

\begin{abstract}
A sexualidade envolve um processo contínuo, e não linear, de aprendizado e reflexão por meio do qual, entre outras coisas, elaboramos a percepção de quem somos. Esse é um processo que se desdobra em meio a construções históricas, sociais e culturais específicas. Nascemos dotadas e dotados de determinadas capacidades biológicas. Todo o resto se constrói e vai se formando ao longo da vida. Por isso, as expressões da sexualidade humana são tão diversas. (BARRETO; ARAÚJO; PEREIRA, 2009, p.115).
\end{abstract}

A diversidade entendida como as diferentes formas de pertencimento a uma classe, gênero, raça, etnia e orientação sexual é cultural e socialmente estabelecida, portanto, aprendidas (apreendidas) ao longo da vida. As diferenças biologicamente determinadas não justificam o surgimento das desigualdades, da discriminação, dos preconceitos, pois são historicamente construídos por influência política, religiosa, econômica.

A homossexualidade, como uma das expressões da sexualidade humana, foi, no final do século XIX, classificada como patologia. Luciana Vieira nos informa que: "As primeiras investigações buscavam identificar as manifestações e causas da homossexualidade com interesse na normalização da vida sexual” (VIEIRA, 2009). Nos dias atuais, o interesse na normalização no contexto institucional é manifestado nas regras e normas estabelecidas ou, simplesmente, nas falas daqueles que controlam o poder decisório: o homossexual pode se identificar como tal desde que não se vista "como mulher", não "desmunheque tanto", não manifeste afeto em público. Tais fatos demonstram que na atualidade acontece da mesma forma como no passado quando

\footnotetext{
"praticava-se uma vigilância moral no que diz respeito a todo comportamento sexual "diferente", porém havia aqueles que eram considerados ainda mais transgressores. Desta forma criavam-se tolerâncias e punições diferenciadas que abrangiam questões de gênero, classe e raça. (VIEIRA, 2009).
}

Desse modo, a diversidade sexual ou se constitui um tabu e não se fala sobre isso ou é tratada como uma patologia. Assim sendo, como é desrespeitada a pessoa com deficiência incapaz de aprender; é também desrespeitada, discriminada a pessoa cuja orientação sexual destoa dos padrões vigentes. A “orientação sexual como categoria que fala sobre a direção do desejo e do afeto" (BORTOLINI, 2012, p.89) e classifica a sexualidade em - homo, hétero e 
bissexual - é parte importante da constituição da própria identidade do sujeito; se este tem a sua sexualidade reprimida ou violentada, as consequências podem se materializar em adoecimentos, insucessos, infelicidade. Já os atos de "transgressão" materializam a resistência.

\section{Considerações Finais}

O incômodo provocado por flagrantes atitudes de desrespeito aos direitos de cidadania no interior da instituição, seja entre pares: estudantes x estudantes, servidores x servidores; ou não: servidores x estudantes/ estudantes x servidores, nos puseram diante da indagação: como pode acontecer tais situações dentro de um espaço que se propõe educativo, formativo? Cientes de que as motivações para tais comportamentos são cultural e historicamente construídas e cotidianamente alimentadas pelo bombardeio midiático disseminador de uma cultura plantada em interesses particulares de uma classe - a classe dominante detentora do poder econômico e político; questionamo-nos acerca da função social da escola - contribuir com a formação da cidadania ativa - conceito contundentemente expresso no Plano Nacional de Educação em Direitos Humanos (BRASIL, 2006) - o que implica na necessidade do desenvolvimento da práxis por parte dos educadores - entendendo-se como educadores todos os atores que atuam no espaço da educação escolarizada envolvidos direta ou indiretamente processo educativo.

Compreender "a escola como campo permanente de aprendizagens diversificadas, de conflitos, de disputas de ideias, posições, crenças, opiniões e orientações” (SILVA, 2012, p.53), como ambiente formador de princípios e valores, como espaço construtor da cidadania requer o envolvimento dos agentes da educação, ou seja, de todos os envolvidos no processo educativo dos adolescentes e jovens que constituem o corpo discente, considerando e reconhecendo, inclusive a efetiva participação daqueles que comportam o quadro demandante de ações, de posturas que lhes assegure a convivência respeitosa como sujeitos de direitos.

Posto que disponhamos de um arsenal legal e ainda nos deparamos com situações de violência contra os sujeitos historicamente alijados dos seus direitos, é possível concluir que não bastam leis, mas, é imprescindível a transformação de mentalidades alicerçadas em ideais pré-concebidos, revestindo-se essa transformação em compromisso social traduzindo em práticas de valorização da diversidade. Muito há que se fazer para que possamos vislumbrar uma sociedade em que a dignidade humana se sobreponha a interesses materiais de uns poucos. 
Não podemos perder de vista que as conquistas até aqui são resultado de árduas batalhas travadas ao longo dos tempos; continuemos, pois, na luta por ver triunfar a vida plena de todas as pessoas.

\section{Referências}

BARRETO, Andreia; ARAÚJO, Leila; PEREIRA, Maria Elizabete (Organizadoras). Gênero e Diversidade na Escola: formação de professoras/es em gênero, orientação sexual e relações étnicoraciais. Livro de conteúdo. Versão 2009 - Rio de Janeiro: CEPESC, Brasília: SPM, 2009.

BENELLI, Silvio José. O internato como instituição total e disciplinar produtora de subjetividades na contemporaneidade. In: MONTEIRO, Rosa Cristina e GONÇALVES, Silvia Maria Melo (Organizadoras). Internato na formação agrícola. Seropédica, RJ: EDUR, 2012.

BORTOLINI, Alexandre. Diversidade sexual, gênero e homofobia na escola: introduzindo um debate. In: RETTA - Revista de educação técnica e tecnológica em ciências agrícolas/ Universidade Federal Rural do Rio de Janeiro. Vol. 3, n. 6 (2012) - Seropédica, RJ: EDUR, 2012.

BRASIL. Secretaria Especial dos Direitos Humanos/Ministério da Educação. Plano Nacional de Educação em Direitos Humanos. 5. tir. atual. Brasília: MEC/SEDH, 2006.

FILIPE, Ana Peixoto. Freud e o inconsciente. O olhar da Psicologia. Abril/2008. Disponível em http://psicob.blogspot.com.br/2008/04/freud-e-o-inconsciente.html.

GOUVÊA, Gabriela Abreu da Silva. Um curso num percurso de inclusão: contribuições da psicanálise e da saúde coletiva. Dissertação (Mestrado) - Universidade Veiga de Almeida, Rio de Janeiro, 2008.

SILVA, Aida Maria Monteiro. TAVARES, Celma. A formação cidadã no ensino médio. São Paulo: Cortez, 2012 (Coleção educação em direitos humanos; v.2).

TEODOSIO, Sheila de Sousa. A inserção de mulheres nos cursos técnicos de Agropecuária e Agroindústria em Igautu-CE. Trabalho de Conclusão de Curso. IFCE Iguatu: 2015.

VIEIRA, Luciana Leila Fontes. As múltiplas faces da homossexualidade na obra freudiana. Revista Mal-estar e Subjetividade - Fortaleza - Vol. IX - Nº 2 - p. 487-525 - jun/2009.

Como citar este artigo (Formato ABNT):

FERREIRA, Eliza Marta G.; MENDONÇA, Antonia E. R. de; ALVES, Maria de Fátima de M. Diversidade Sexual no Ambiente Escolar: o exemplo do campus Iguatu do IFCE. Id on Line Rev.Mult. Psic., 2018, vol.12, n.40, p.503-511. ISSN: 1981-1179.

Recebido: $16 / 04 / 2018$

Aceito 25/04/2018 